AUG 242000 ENGINEERING DATA TRANSMITTAL

2. Io: Receiving Organization?

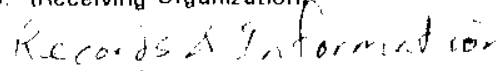
$4 \%$, 1 5. Proj./Prog./Dept./Div.

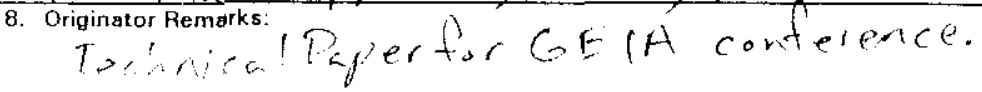

6. Dosign At

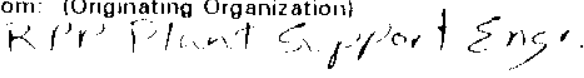

EDT

Page 1 of 1 702356

4. Fielated EOI No.:

$$
\sqrt{1} / A
$$

7. Purchase Order No.

$$
N A
$$

9. Equip./Component No::

$$
N ? \mathrm{~F}
$$

10. System/Bldg./Facility

$$
\text { N) } / A
$$

12. Major Assm. Dwg. No.

$$
\text { N) } / A
$$

11. Receiver Remarks

11A. Design Baseline Document? $\square$ Yes $\square$ No

13. Permit/Permit Application No

Ni

14. Required Response Date

$$
\rightarrow 1,2,1,1,
$$

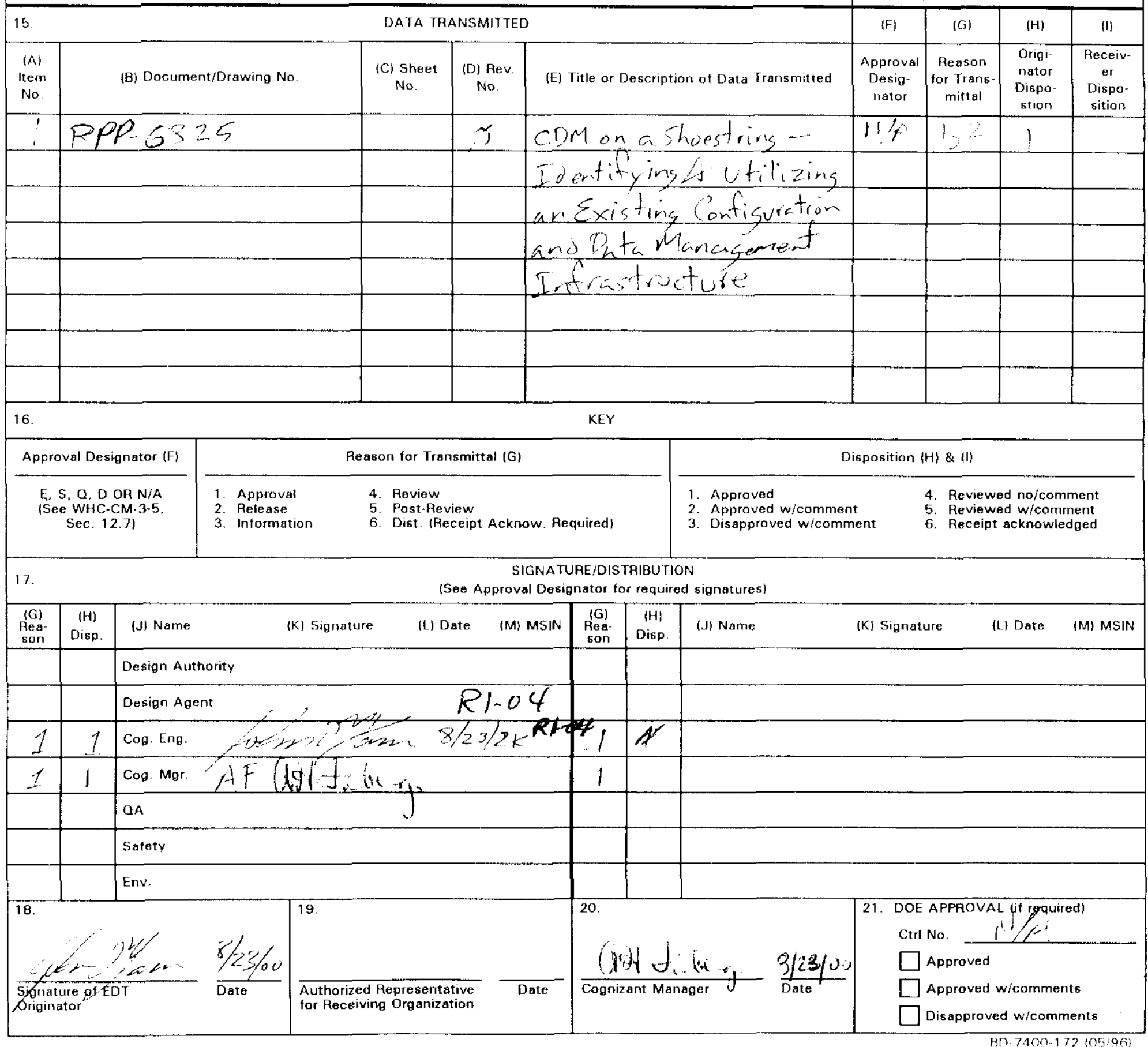




\title{
CDM on a Shoestring - Identifying and Utilizing an Existing Configuration and Data Management Infrastructure
}

\author{
John M. Vann \\ CH2M Hill Hanford Group, fric. \\ Richland, WA 99352 \\ U.S. Department of Energy Contract DE-AC06-99RL14047
EDT/ECN: $\quad 702356$
UC:
Cost Center: 71300
Charge Code: $106399 \mathrm{AJ} 60$
B\&R Code:
Total Pages:
16. 37.24 .06
Key Words: configurat ion data managcmont infrastructuro biA

Abstract:

TRADEMARK DISCLAIMER. Reference herein to any specific commercial product, process, or service by trade name, trademask, manufacturer, or otherwise, does not necessarily constitute or imply its endorsement, recommendation, or favoring by the United States Government or any agency thereof or its contractors or subcontractors.

Printed in the United States of America. To obtain coptes of this document, contact: Document Control Services, P.O. Box 950, Mailstop H6-08, Richland WA 99352, Phone (509) 372-2420; Fax (509) 376-4989
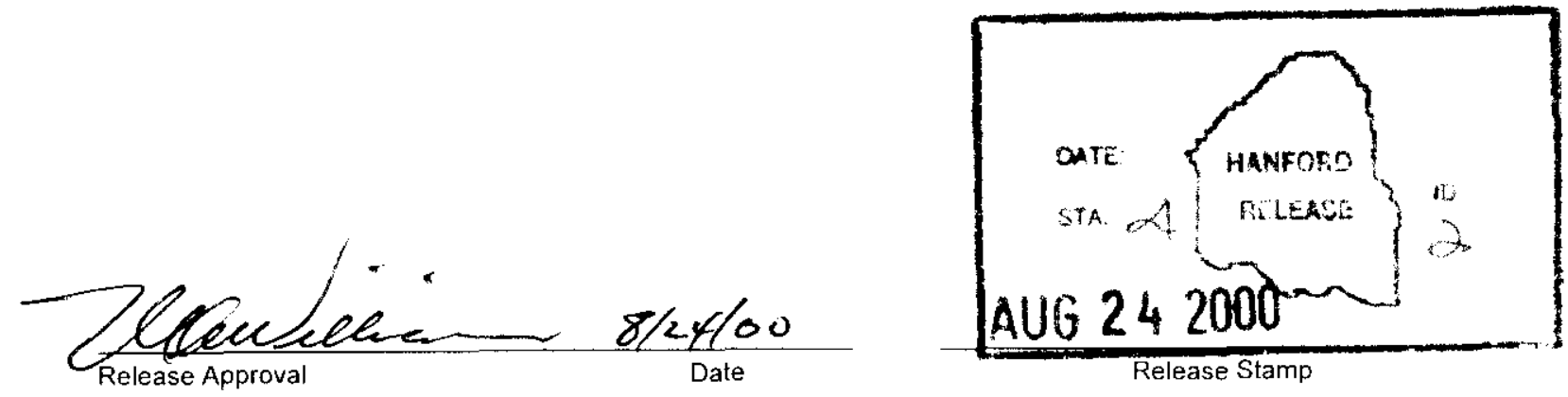

Approved For Public Release 


\title{
CDM on a Shoestring
}

\section{Identifying and Utilizing an Existing Configuration and Data Management Infrastructure}

\author{
John M. Vann \\ Planning and Integration \\ Configuration Management Lead \\ P.O. Box 1500 \\ R1-04 \\ Richland, WA \\ 99352-1505 \\ TEL: (509) 373-4936 \\ FAX: (509) 376-7951 \\ E:mail: john_m_vann@rl.gov
}

Prepared for the U.S. Department of Energy

Assistant Secretary for Environmental Management

\section{CH2MHILL}

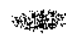

P.O. Box 1500

Richtand, Washington

Contractor for the U.S. Department of Energy

Office of River Protection under Contract DE-AC06-99RL14047 


\section{CDM on a Shoestring}

\section{Identifying and Utilizing an Existing Configuration and Data Management Infrastructure}

\section{Abstract}

The spreading need for and use of configuration and data management (CDM) standards has highlighted a number of challenges to the companies that need to implement those standards. For companies and organizations that are new to CDM or have limited CDM capabilities, one of the major dilemmas faced is identifying how and where to start. In many cases there is a need to contend with a legacy of poonly identified items and information and an immature or non-existent CDM infrastructure (processes, procedures, people, \& information systems). To the company management and CDM professional this poses a seemingly insurmountable task of putting in place a CDM infrastructure that provides the needed benefits while keeping within an acceptable cost and schedule. This paper deals with initially establishing the CDM infrastructure using the tools that a company already has available. The paper identifies features of common software applications that can be used to implement CDM principles.

Please note that this document does not represent a corporate position of $\mathrm{CH} 2 \mathrm{M}$ Hill, Incorporated. Rather it is an approach that has been developed via the compilation of the experiences and lessons learned of numerous individuals over a span of years. It is one of many possible approaches for implementing CDM principles.

\subsection{Introduction}

Implementing configuration and data management standards requires that the items and related information that need to be controlled be identified, placed under control, and then maintained and statused. To do this both a CDM process (e.g., as reflected by a set of procedures procedure) and implementing mechanisms (e.g., people, and information management resources) are required.

Unfortunately companies are faced with a serious dilemma when establishing and maintaining configuration and data management processes. If a company does not already have the processes and mechanisms in place, it is faced with the seemingly insurmountable task of establishing them and then running them. The option of procuring the necessary processes and mechanisms is often fraught with high up-front expenses and seems to involve just as much effort as if the company did the work to create the processes and mechanisms.

This paper attempts to pose some possibilities for getting over these hurdles. Suggestions involve taking things a step at a time rather than building or buying the processes and mechanisms in one fell swoop. To do this advantage is taken of the tools that a company already has available but may not be fully aware of. 


\subsection{The Approach}

A basic approach for establishing a CDM infrastructure is to make the most use of what is currently on-hand. This approach avoids the high costs and schedule impacts of procuring Commercial Off-The Shelf (COTS) systems or having such a new system built. Use of existing systems also reduces the need for additional training. Prioritizing improvements to the existing infrastructure can further reduce cost and schedule impacts.

Once the CDM infrastructure has been established it can be used to initiate identification and control of the configuration items and information. This allows time for planning and acquiring a mature CDM infrastructure either by continuing to enhance existing capabilities or by procuring or building new CDM systems. This examination of the existing infrastructure also provides a wealth of knowledge of related needs.

While use of existing capabilities may seem to perpetuate existing problems and typically lacks the nifty bells and whistles, it allows efforts to be focused on those existing problems. This enables and encourages development of a better understanding of CDM needs. This information can also be used to acquire CDM capabilities that do a better job of meeting those needs than would be possible, if the company bought or built a new CDM system without performing these steps.

This gives the following basic steps to establish a CDM infrastructure:

1. Identify CDM infrastructure needs \& requirements. Review requirements documents and interview users and customers.

2. Identify the existing CDM infrastructure. Inventory CDM-related procedures, applications, and resources (people).

3. Identify and evaluate the existing capabilities. Develop a list of available capabilities that shows redundancies and insufficiencies. Perform a gap analysis of the available capabilities vs needs \& requirements.

4. Develop a realistic plan for eliminating duplicate acquiring missing functions. Start the plan at "integrate and enhance existing infrastructure" and build up to "acquire mature infrastructure."

5. Implement the plan.

Since the intent of this paper is to make the most of existing capabilities, the acquisition and use of resources from external sources (e.g., buying a COTS CDM application) is not addressed. Performance of the steps included here would also be beneficial as a precursor to acquiring commercial CDM resources. This is because these steps build a better knowledge base for the acquisition and subsequent installation and implementation. 


\subsection{Identify Needs \& Requirements}

The makeup of CDM infrastructure is reliant upon the needs and requirements that it must fulfill. In order to keep this paper short, this step will be fairly succinct. It really deserves a paper of its own. The act of identifying needs and requirements can provide a wealth of CDM knowledge about the nature of the needs and requirements as well as the CDMrelated processes that have been created to meet them.

It is important to capture and keep the data gathered from this effort. Portions of this knowledge will be used in stages to identify the existing CDM infrastructure, improve existing CDM and business processes, plan long term improvements, develop specifications and for future acquisition of CDM systems, and to develop criteria to test the maturity of the available CDM infrastructure.

It can be very helpful to use the data to build a fairly simple model of the CDM infrastructure and add to it as information is gained. The model provides a way to store and organize the knowledge obtained from these CDM efforts. The model be used to record/map the sources of requirements and needs, attach usability data, and to locate and highlight redundant and missing functions. Portions of the model can be used when communicating with management and various organizations to further their understanding of what is being done relative to CDM and how the can benefit from and help in those efforts. Over the long term even a simple model can be developed into a fairly powerful tool.

\subsection{Identify Needs and Requirements Sources}

Needs and requirements are typically the result of specific contractual commitments, requirements derived form those, business rules, and the processes used to perform work. In the case of business rules and work processes, the needs and requirements tend to exist in both written and unwritten forms. Knowledge of the nature of these sources is critical to being able to properly prioritize and respond to the needs and requirements. For example: a CDM feature that helps show compliance to a state law might be given a higher prionity than a feature that is used solely for process improvement.

\subsection{Identify Written Needs and Requirements}

Needs and requirements that pertain to which information must be managed and to how that information is to be managed can be identified by reviewing the written material that the company uses to do business. This includes such things as:

- Contracts,

- Policies, Plans, and Procedures,

- Management Directives,

- Applicable Codes and Standards

Key data to be gathered include but are not limited to:

- What information is being required,

- What is the source of the requirement (e.g., contract clause \#\#, procedure \#),

- What form must the information be in, 
- Who is responsible for providing the information,

- Who is the recipient of the information,

- Which processes must the information go through (e.g., produce, validate, approve, deliver, and accept)?

With this knowledge a list of the data needed for identifying and controlling the configuration information can be developed. This "meta-data" is typically entered into a database that relates it to the applicable configuration information. Some of the meta-data is also attached to the configuration information to uniquely identify it and assist the user. There is also an opportunity to identify data that is being gathered but is not needed.

The last of the bulleted data above is key to the topic of this paper. Examining the written requirements to determine which processes the information goes through and the metadata required by those processes allows construction of a simple model of the company's information management processes, which are a major part of the CDM infrastructure.

\subsection{Identify Unwritten Needs and Requirements}

Identification of unwritten needs and requirements is just as important. Conversations with workers and a review of the information that they keep handy to do their work is likely to identify configuration information and/or meta-data that is needed but not identified in contracts, procedures, etc.

The key data gathered in this step is similar to that gathered for written needs and requirements. Additional pieces of data are the importance and degree of use of the unwritten need or requirement. This can be used in the future to determine whether to document it in a contract, procedure, etc

As part of this step, data should also be gathered about which configuration information and meta-data is needed on a regular basis by the worker and in what form it would be of most use to the worker. The knowledge gathered is then factored into that gathered from reviewing the written sources and added to the CDM infrastructure model.

\subsection{Identify the Existing CDM Infrastructure}

Identification of CDM capabilities requires an understanding of the written and unwritten practices people are performing, the capabilities available in the software applications that people commonly use, and the CDM related skills that people have developed. To identify CDM capabilities first identify the electronic and manual tools used to develop, manage, and distribute configuration information. These tools include such things as electronic and physical file cabinets, word processing software, databases, logs, reproduction tools, and distribution mechanisms. The following is a brief list of the steps involved.

- Review procedures and interview personnel to identify the processes that handle configuration information. Much of this knowledge can be gathered while identifying CDM needs and requirements.

- Examine each process to identify the electronic and manual information management tools that it uses.

- Identify who is responsible for maintaining each tool.

- Identify the types of users for each tool (e.g., by organization and/or discipline). 
- Summarize the basic purpose and function of each tool.

- Get an approximate measure of how much each tool is used and its cost.

- Determine the type of information managed by each tool.

- Identify the meta-data each tool uses to manage information.

- Determine the inter-relationships between the various tools.

- Determine the relationships between the various tools and the CDM written and unwritten processes.

Once the effort to identify and evaluate existing tools has begun the steps will tend to run concurrently and be somewhat re-iterative. As each tool is identified and examined, the knowledge gained will tend to improve the understanding of how other tools are used. At times this will generate questions about other tools, some of which have already been examined. This re-iterative performance can lead to an over-extensive examination of the tools. In order to avoid such an excess of effort, it is wise to regularly check the knowledge gained against the list of needs and requirements. It is also helpful to filter out redundant tools and processes.

\subsection{Identify and Evaluate Existing Capabilities}

Now that a basic understanding of the needs and requirements has been developed and the related processes and the mechanisms (tools) used by those processes have been identified, it is time to determine the capabilities of those tools.

The fact that a capability exists does not necessarily mean that people are knowledgeable of it or are using it. Therefore it is necessary to identify the existing tools and the tools' capabilities that are being used. The tools are then examined to find the capabilities that are available but are not in use. The knowledge gained here is used to refine the understanding of the CDM infrastructure and any model that has been have developed.

Due to the time and paper limitations this paper will address the capabilities available in the software applications that people commonly use. The capabilities are available in varying degrees in other commercially available software.

\subsection{Identify Capabilities in Use}

An examination of how each tool is used provides an understanding of some of its capabilities. The following is a brief list of the steps involved.

- Determine the basic way that the tool is used to manage information.

- Identify the meta-data that is collected and used when operating the tool. This may vary for different types of configuration information.

- Identify the purpose of the meta-data (e.g., to identify who can approve the document, to index the information files, to provide performance data to management, or not used),

- Identify the customers for these capabilities and the meta-data. 


\subsection{Evaluate In-use Capabilities}

Develop a picture of how tools are being used to manage information and implement work processes. Evaluate the in-use capabilities to identify areas for improvement. This includes elimination of redundancies, consolidation of tools, and improving use and useability. Compare the capabilities of each tool to the set of needs and requirements and identify gaps and insufficiencies.

\subsection{Evaluate Unused Capabilities}

With an understanding of how the tools are being used and the gaps that exist in them it is possible to do an informed search for missing capabilities. To this end each of the tools is evaluated to identify capabitities that exist but are not being used. Specific attention is paid to finding capabilities that can be used to fulfill CDM needs and requirements. The section on "Identifying Existing Capabilities" includes an example of the types of capabilities that can be found.

The software applications commonly used in today's office place often have CDM features that are under-utilized. The following are some examples.

\subsubsection{Document Identification, Trace-ability, and Status Accounting}

Many standard word processing, database, and spreadsheet software applications provide the means for entering and tracking meta-data. While the specific capabilities vary, typical types of meta-data tracked include information that correlates documents to items, people, organizations, customers, accounts, and other documents and tell when a document was first produced, when it was last changed, who changed it, and what they changed. Common locations for meta-data include file properties, document summaries, headers, comments, notes, and special fields.

These fields hold both automatically generated and author-defined information about the document. Some applications allow the fields to be tied to document content such that all occurrences of a field in the document will be updated when the property field is up dated. With judicious use, the fields may store and status just about any form of information that a CDM professional would want tied to a document.

Table 1 gives examples of meta-data that can be tracked via automatically generated or user selectable fields in a few common document viewing and editing applications. In addition to the fields listed in Table 1, each of these applications allow information to be imbedded in the document in the form of notes, comments, and other data fields.'

\subsection{Change Control \& Markup}

As well as having the capability to automatically number file revisions/versions, many office applications include the ability to control and track changes as they are made to the document. The automatic markup capabilities range from redline and strike-out to the ability to automatically do complex formatting and annotation based upon what was changed, who changed it, and how it was changed.

With the increase in publishing via the web, object linking and hyper linking capabilities have been built into common office programs. The use of object linking allows a piece of information to be shared amongst a number of documents. This enables the updating of all of the documents that use the information by changing a single document file. Use of 
the change tracking and properties capabilities provides for the tracking changes and their impacts.

\subsubsection{Controlled Distribution}

Posting the native files of documents on a shared read-only server, can be used to provide users with controlled access to the most recent version of the document. This encourages people to use the document form the sever, reduces the tendency for people to maintain their own copies, and provides the author with the original as a basis for changes. It also allows and encourages the sharing of information between documents (e.g., linking), which reduces duplication and conflicts.

\subsection{Develop a Realistic Plan}

By now the CDM infrastructure model has grown to show what information is being managed; the processes, mechanisms, and tools that are used to manage it; where and how the needs and requirements are met, where gaps exist and how they can be filled, and what redundancies and excess capabilities exist. The model represents the desired architecture of the CDM infrastructure and includes an overlay of where trimming and improvements are needed to get to that desired state. It is now possible to develop a plan for the cost-effective improvement of the CDM infrastructure. Of equal importance, the model can be used to train employees and educate customers.

\subsection{Putting it All Together}

Using the capabilities listed above a basic CDM infrastructure can be constructed that will enable implementation of CDM principles to begin. The resultant CDM infrastructure could vary across a wide range of possible architectures.

A very simple and basic CDM architecture might consist of the following components:

- A common set of document preparation applications (word processing, spreadsheet, graphics, presentation, database, planning, etc.),

- One or more file servers to contain the electronic files of the configuration information.

- Specific location(s) for manual files.

- A user interface (e.g., Netscape, Intemet Explorer, Windows Explorer) for locating and retrieving files from the file server.

Using these components a basic CDM system could be implemented as follows:

- Maintain a cross-referenced and linked list of configuration items, configuration information, owners, and miscellaneous tracking data (e.g., using a spreadsheet or database).

- Place all configuration information files in specific places with reliable administrators. Maintain a set of "current" files that always have the same narne and path. Archive old files to another location.

NOTE: Figure 1 provides an example mechanism for making configuration information accessible using the following techniques. 
- Provide users with a list of information resources. Where possible include links to those resources. Otherwise provide instructions on how to access the resource. See Figure 2 for an example.

- Build an index and table of contents for the users that has hyperlinks each configuration information entry to the "current" file that contains the information. See Figure 3 for an example.

- Where configuration information is not available electronically (e.g., it is in a file cabinet or isolated location) identify it in the electronic index and table of contents with a note of where it is and directions on how to access it.

- Use the file meta-data to store, post, and update the CDM data used to track, control, and access for the configuration information (e.g., document - item -owner references). See Table 1 and Figures 4 - 6 for examples.

- Use object linking to share information between docurnents.

- Hyperlink document content to references and source material. Add a hyperlink to email the author and/or approval authority with comments or for help.

- Where it is desirable, convert basic drawings and figures to html and add links from the image items to related information.

- Use an HTML project application to provide a map of the hyperlinked documents.

- Provide instructions and training about the CDM architecture its functions (e.g., the above functionality).

\subsection{Implement the Plan.}

Successful planning is a topic for that would require a number of papers for decent coverage so l'll be very brief here. "Plan what you do - do what you plan." Once the work starts, it is far too tempting to add a helpful feature that will only take a small amount of effort and time. Such small adjustments during implementation have been known to add up rapidly and at times have caused faily major validation problems. Scope creep has resulted in the failure of many software projects. Concentrate on establishing the overall CDM infrastructure and save the tweaking for after the planned changes have been made. Then make the improvements using a defined change control process. 


\section{Table 1. Meta-data Examples}

Commonly available commercial software may include fields that can be used to identify and maintain the meta-data that is necessary to control configuration information. This table lists some of the fields available in three commonly used applications.

\begin{tabular}{|c|c|c|}
\hline $\begin{array}{c}\text { Corel }^{\mathrm{TM}} \text { WordPerfect } \\
\text { (Document Summary - Fig . 4) }\end{array}$ & $\begin{array}{c}\text { Microsoft }^{\mathrm{TM}} \text { Word } \\
\text { (File Properties - Fig. 5) }\end{array}$ & $\begin{array}{l}\text { Adobe }^{\mathrm{TM}} \text { Acrobat } \\
\text { (General Info- Fig. 6) }\end{array}$ \\
\hline $\begin{array}{ll}\circ & \text { Abstract } \\
\text { Account } \\
\text { Address } \\
\text { Attachments } \\
\text { Author } \\
\text { Authorization } \\
\text { Bill to } \\
\text { Blind copy } \\
\text { Carbon copy } \\
\text { Category } \\
\text { Creation date } \\
\text { - Revision date } \\
\text { Descriptive name } \\
\text { Descriptive type } \\
\text { Document number } \\
\text { Keywords } \\
\text { - Purpose } \\
\text { Revision number } \\
\text { Source } \\
\text { Subject } \\
\text { Typist }\end{array}$ & 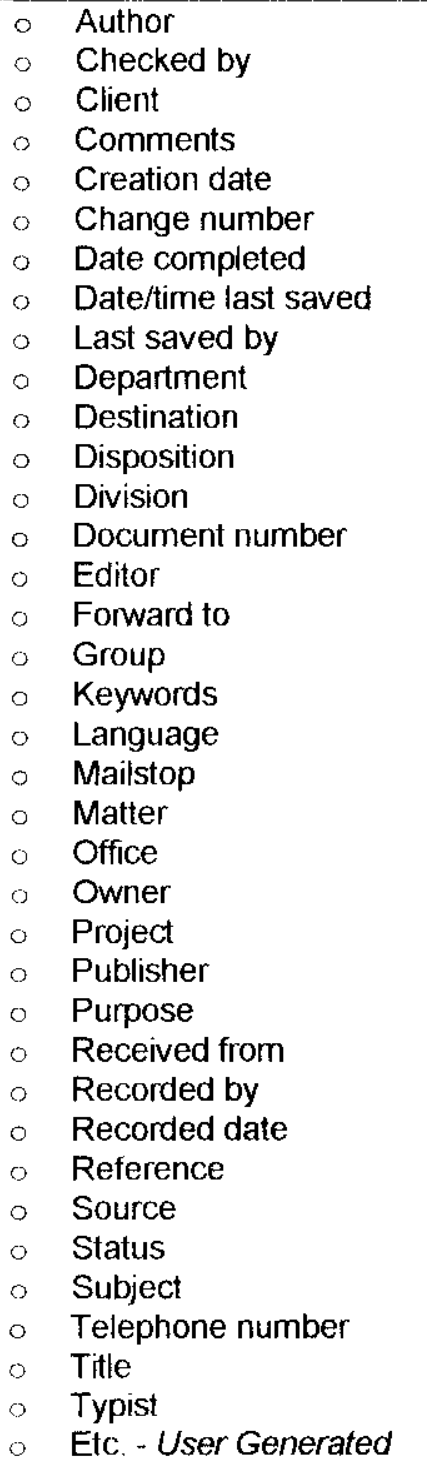 & $\begin{array}{ll}\circ & \text { Author } \\
& \text { Binding } \\
& \text { Created date/time } \\
& \text { Modified date/time } \\
& \text { Title } \\
0 & \text { Keywords } \\
& \text { Subject }\end{array}$ \\
\hline
\end{tabular}


RPP-6825

Rev. 0

Figure 1. Making Information Accessible

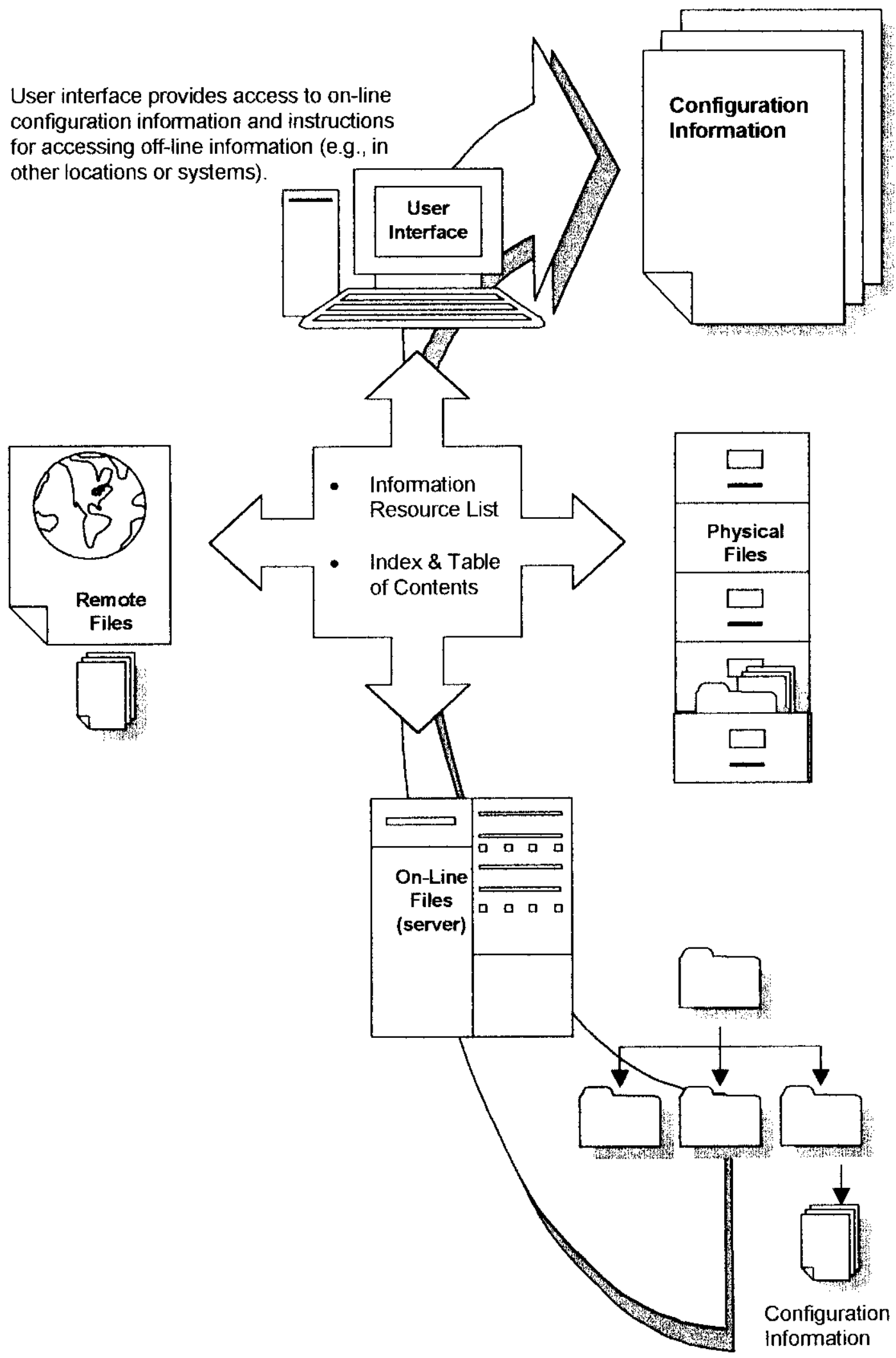


RPP-6825

Rev. 0

Figure 2. Information Resource List Example

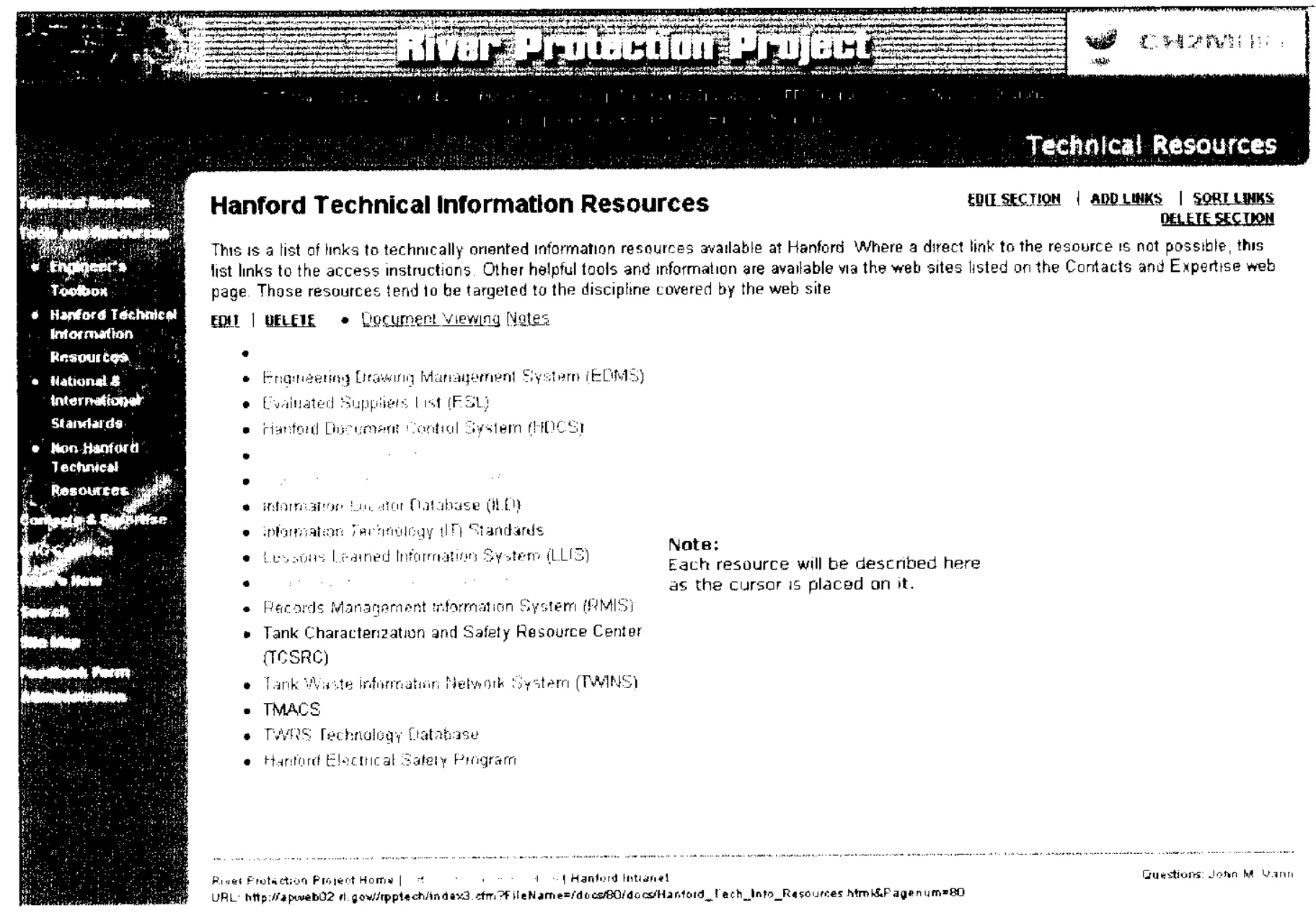


Figure 3. Configuration Information List Example

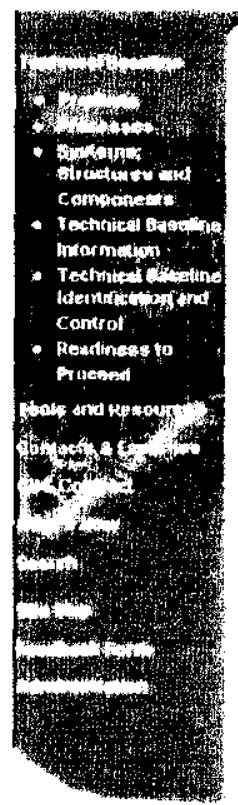

\section{Readiness to Proceed}

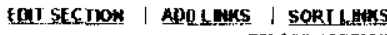

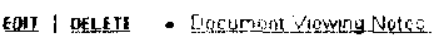

The table below provides inks to the documents that suppon the Rmer Protection Project Peadilus: t:

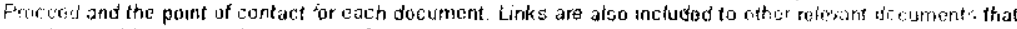

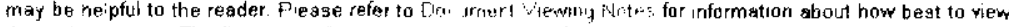

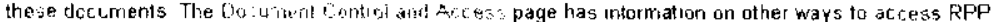
documents The RTP docurnent folder can be sparched by pressing the button helow and then, when the folder opens, pressing : th?

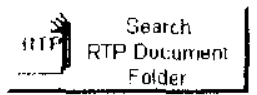

Readiness to Proceed Documents

Document:

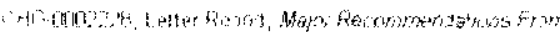
Fin

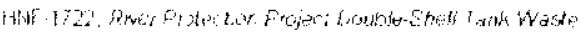

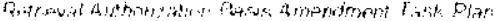

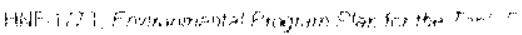

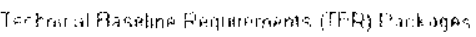

- Techorical Baseline Reuguremerits

- Cost Estimating input Sheets

- FKAGNEIS

- P3 Schedules
Contact:

Tony Dilubent? $373-9407$

John Harris

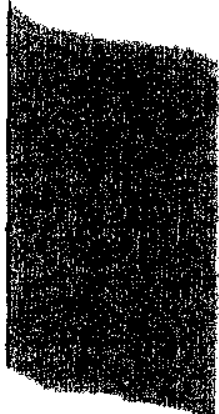

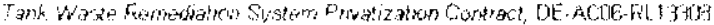

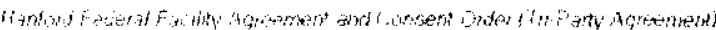

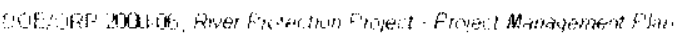

rontaci. Don Alexander (322-2453) or Steve Seeman (376.1178)

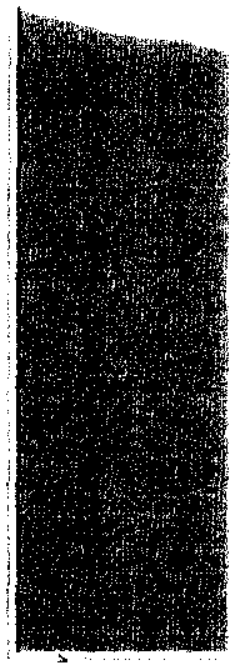
Anne-Mane Choho (3720200)

Atternalive Generatium Analysis an tiade Sludies dfe martaged within the Hanfurd Document Control Syotem (see the instructions abore this table) Contact. Anne-Marie Choho (372-8280)

Project execution and maragement plarts are managed within the Hantord Document Controi System (see the instruction's above this table) Contaci Arire-Marle Cnoho ( $3 r 2.84 t y)$

Project słstems engineering documents are managed withın the Hanterd Document Control System (see the instruct:ons above this table) Contact Jo Ferguson (372-8246)

The HNF-SO-MF-SRID-001, Tank Waste Remediation Syslems Standards and Requirement: Identdication

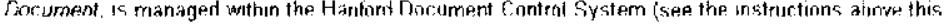
(able)

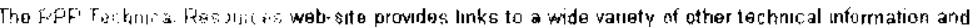
resources that may be of use to the user

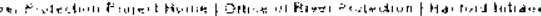

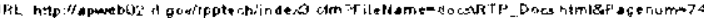

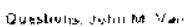

Lat Updated Oafs 3 rovit: 1424 
Figure 4. WordPerfect $($ Document Summary

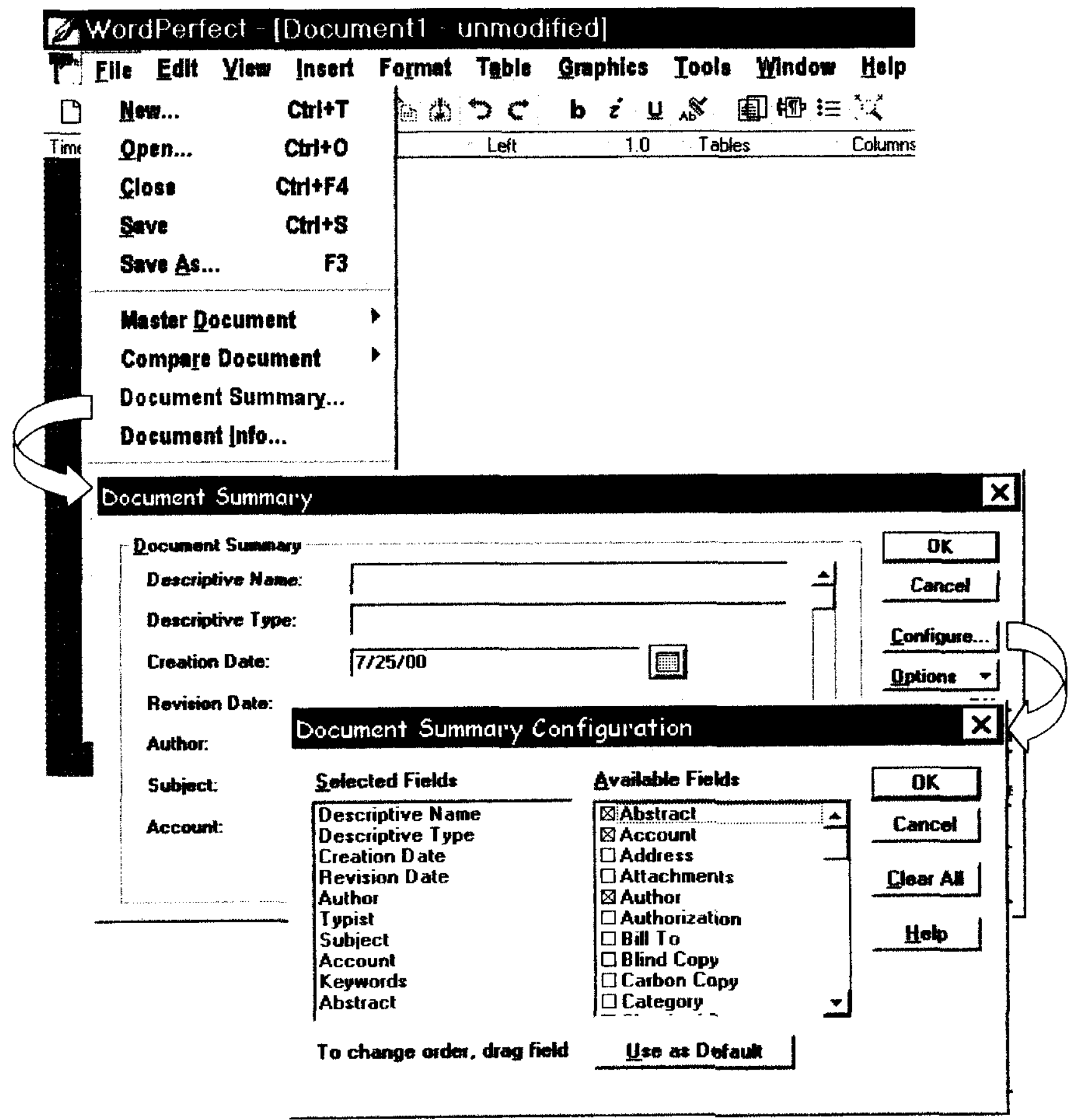


Figure 5. Word $\circledast$ File Properties

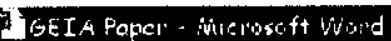

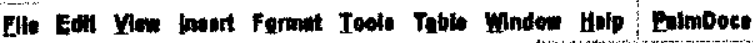

D

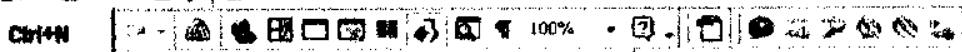

osen...

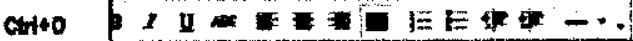

$\left[\begin{array}{c}\text { Geas } \\ \text { a som } \\ \text { sure An... }\end{array}\right.$

A Eme wab Pagt...

Vyrolono...

Wod Puye Provin.

Export I.

Page 8chip...

T. Print Proylas

8 Briat..

antp

aromer

anow for.

send

Properties

1 uilint Finel.

2 Pansonal Prep

3) U:L.IPImese of

4 cemmonowar.

2 CHMivoura.

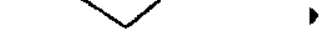

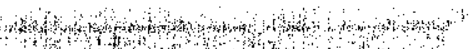

Cutto
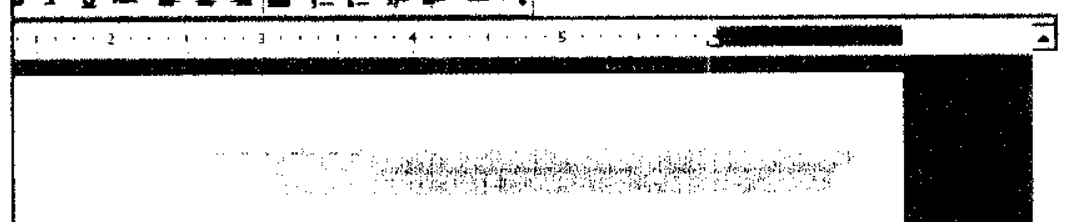

EIA Paper Properties

General Summary |Statistics | Contents | Custom |

Itle: CDM on ast GEI A Paper Properties

Subject: $\longdiv { \text { Identifying: } }$

General | Summary | Stakistics | Contents Custom |

Buthor: $\longdiv { J o h n }$ M. Van

Name:

Monager: Bob Hutchir:

Company: $\longdiv { \mathrm { CH } _ { 2 } M \mathrm { Hill } _ { \overline { c } } }$

Category: Professional

Keywords:

Comments: $\longdiv { \text { For GEIA } 3 4 }$

Properties:
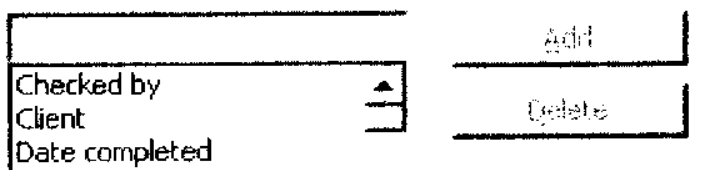

Department

Destination

Disposition

Iype:

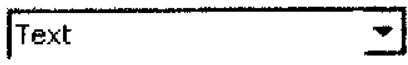

Yakue:

$\Gamma$ Link to content

Hyperlink

base:

Template: Professional

$\Gamma$ Saye preview picture

\begin{tabular}{|c|c|c|}
\hline Name & Value & Type \\
\hline Client & Governmen... & Text \\
\hline Date com... & August $8,2 \ldots$ & Text \\
\hline Department & Program M... & Text \\
\hline Destination & Dalla, $T \times \subset \ldots$ & Text \\
\hline Disposition & Pending Ap... & Text \\
\hline Documen... & RPP-6825 & Text \\
\hline Language & English, US & Text \\
\hline Mailstop & R.1-04 & Text \\
\hline Office & $2750 / C-106$ & Text \\
\hline
\end{tabular}


RPP-6825

Rev. 0

Figure 6. Adobe Acrobat ${ }^{\circledast}$ General Info

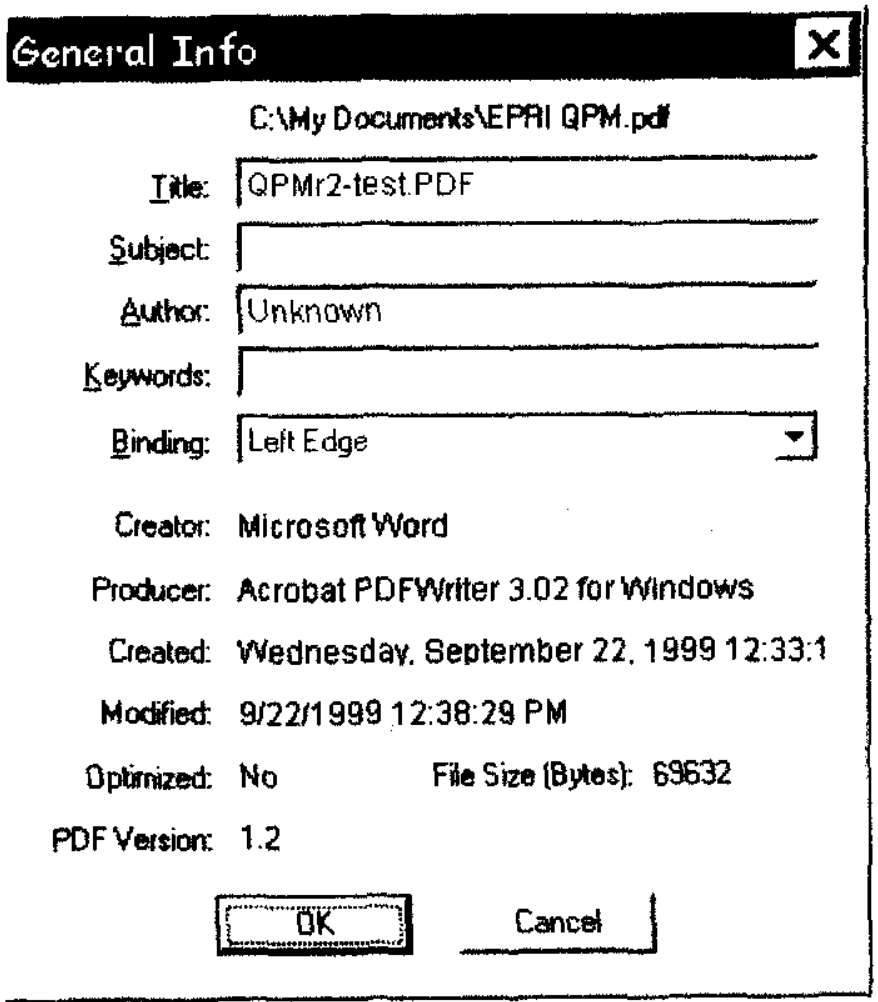

